\title{
Correspondence
}

\section{Prolonged delirium after propofol}

To the Editor:

We would like to report a case in which a healthy 19-yr-old patient had an extremely unpleasant emergence following an anaesthetic for knee surgery where maintenance was carried out by propofol infusion.

Our patient had two prior uneventful anaesthetics maintained by entlurane and isoflurane respectively. On this occasion propofol was used for induction and maintenance (total dose of $400 \mathrm{mg}$ ) with $\mathrm{N}_{2} \mathrm{O} / \mathrm{O}_{2}$ and the duration of the anacsthetic was $35 \mathrm{~min}$. On the way to the PACU the patient became agitated and thrashed around uncontrollably. During her periods of agitation which lasted for several minutes with 1-2 min intervals between, the patient was treated with incremental doses of midazolam (total $6 \mathrm{mg}$ ) diazepam (total 50 $\mathrm{mg}$ ), and diphenhydramine (total $50 \mathrm{mg}$ ) and required four or five people to hold her down. Her heart rate increased up to $170 \mathrm{bpm}$ and her temperature to $38.5^{\circ} \mathrm{C}$. After four to five hours of violent thrashing, the patient suddenly became alert, calm, responsive to verbal stimulation and had no recollection of the entire event.

The only drugs our patient received in addition to propofol were nitrous oxide, lidocaine, and fentanyl, all of which she had received without untoward effects during previous anaesthetics. Our only explanation of this episode is an idiosyncratic reaction to propofol, similar to previous descriptions, ${ }^{1-5}$ and wonder if readers have any other suggestions.

Farida Gadalla MD

Department of Anesthesiology

The New York Hospital - Cornell Medical Center

525 East 68th Street, \#A-1050

New York, New York 10021

James Spencer MD

Department of Anesthesiology

The New York Downtown Hospital

170 William Street

New York, New York 10021

\section{REFERENCES}

1 Young $P N$. Hallucinations after propofol (Letter). Anacsthesia 1988; 43: 170.

2 Bricker SRW. Hallucinations after propofol (Letter). Anaesthesia 1988; 43: 171.

3 Brazzalotto I. Effects of propofol (Letter). (French) Ann Fr Anesth Reanim 1989; 8: 388.

4 Thomson $K D$, Knight $A B$. Hallucinations after propofol (Letter). Anaesthesia 1988; 43: 170-1.

5 Reynolds $L M$, Koh $J L$. Prolonged spontaneous movement following emergence from propofol/nitrous oxide ancsthesia. Anesth Analg 1993; 76: 192-3.

\section{Prevention of hypotension after propofol for rapid sequence intubation}

To the Editor:

El-Beheiry et al.' found that volume loading maintained haemodynamic stability during rapid sequence induction. with propofol and succinylcholine. Although they found few previous reports of propofol as the sole intravenous agent with succinylcholine for rapid sequence induction, their haemodynamic results were similar to that observed when propofol was used for rapid sequence induction at caesarean section. ${ }^{2.3} \mathrm{We}$ found that $500 \mathrm{ml}$ Ringer's lactate solution during induction of anaesthesia contributed to satisfactory haemodynamics although admittedly our pregnant patients would have different cardiovascular physiology compared with nonpregnant patients.

Most pure hacmodynamic studies with propofol have purposely waited after induction of anaesthesia to document the haemodynamic changes. Hypotension is usually maximal at two to three minutes and it is more marked than with other intravenous agents. ${ }^{4,5}$ However, these findings are not as clinically relevant during rapid sequence induction when the coincident administration of succinylcholine, early cricoid pressure and tracheal intubation would all counter the hypotension caused by propofol. It is logical that fluid loading would prevent hypotension because propofol causes peripheral vasodilation. Effective volume loading will also prevent decreases in cardiac output. ${ }^{6}$ It is thus important that patients for emergency surgery are not dehydrated before using propofol for rapid sequence induction.

Compared with thiopentone, propofol is also better at attenuating the catecholamine and hypertensive response after tracheal intubation. ${ }^{2.3 .5}$ Propofol is a very useful agent for rapid sequence induction of anaesthesia and volume loading is an important part of the technique.

T. Gin FRCA FANZCA MD

Department of Anaesthesia and Intensive Care

Prince of Wales Hospital

Chinese University of Hong Kong

Shatin, Hong Kong

REFERENCES

I El-Beheiry H, Kim J, Milne B, Seegobin R. Prophylaxis against the systemic hypotension induced by propofol during rapid-sequence intubation. Can J Anaesth 1995; 42 . 875-8.

2 Gin T, Gregory MA, Oh TE. The haemodynamic effects of propolol and thiopentone for induction of Caesarean section. Anaesth Intensive Care 1990; 18: 175-9.

3 Gin T, O'Meara ME. Kan AF, Leung RK, Tan P, Yau G. Plasma catecholamines and neonatal condition after induction of anacsthesia with propofol or thiopentone at Caesarean section. Br J Anaesth 1993; 70: 311-6.

$4 \mathrm{Mc}$ Collum JS, Dundee JW. Comparison of induction characteristics of four intravenous anaesthetic agents. Anaesthesia 1986; 41: 995-1000. 